\title{
Dándole la palabra: nuevas modalidades de liderazgo entre mujeres guaranies del noroeste argentino $^{1}$
}

Natalia Castelnuovo Biraben ${ }^{2}$

CONICET- Universidad de Buenos Aires, Buenos Aires, Argentina ${ }^{3}$ naticastelnuovo@gmail.com

Recibido: 30 de septiembre de 2013

Aceptado: 2 de diciembre de 2013

Artículo de revisión en el cual se presentan los resultados de investigación de la tesis de Maestría y Doctorado de la autora en el área de Antropología Social. Ambos estudios se apoyaron en una amplia revisión bibliográfica sobre la producción etnohistórica y etnográfica acerca de los guaranies en general y la participación politica femenina en particular. Estas investigaciones fueron financiadas por el Consejo Nacional de Investigaciones Científicas y Técnicas (CONICET) y por los Proyectos UBACyT "Representaciones sociales y procesos políticos: análisis antropológico del lugar del ritual en el dominio político" (2004-2008) y "Procesos políticos, relaciones personales, e instituciones estatales. Análisis etnográfico y comparativo de la producción social de distintos niveles de organización político-administrativa” UBACyT (2011-2014), dirigidos por el profesor M. Boivin.

2 Doctora de la Facultad de Filosofia y Letras de la Universidad de Buenos Aires, área de Antropología Social y Magíster en Antropologia Social del Instituto de Desarrollo Económico y Social (IDES) y el Instituto de Altos Estudios Sociales (IDAES) de la Universidad Nacional de San Martín.

3 Becaria Posdoctoral del Consejo Nacional de Investigaciones Científicas y Técnicas. Su proyecto se cimienta en la Sección de Antropología Social del Instituto de Ciencias Antropológicas de Filosofia y Letras de la Universidad de Buenos Aires. 


\title{
Dándole la palabra: nuevas modalidades de liderazgo entre mujeres guaranies del noroeste argentino
}

\section{Resumen}

Desde la década de 1990 en adelante las mujeres guaraníes del noroeste argentino han comenzado a demandar mayor participación al interior de sus comunidades así como dentro de las organizaciones indígenas. Más allá de que algunas mujeres hayan logrado obtener el reconocimiento de sus pueblos asumiendo diversas posiciones de liderazgo, lo cierto es que se trata de un proceso de cambio bastante resistido y cuestionado desde los espacios de organización indígena que tradicionalmente, han sido espacios masculinos. Esto nos lleva a explorar los roles asignados a las mujeres dentro del pueblo Guaraní. A través de la adopción de una mirada etnohistórica y etnográfica, nuestra intención es poder dar cuenta de ciertas transformaciones en las relaciones de género que han hecho posible que mujeres indígenas estén ejerciendo su derecho a participar de la vida pública de sus pueblos. Las modalidades que asume el liderazgo de las mujeres guaraníes se analizan a través de sus propias experiencias de participación como autoridades en organizaciones políticas comunitarias y organizaciones interétnicas regionales.

Palabras clave: liderazgo; mujeres guaranies; relaciones de género; derechos; noroeste argentino

\section{Giving "La Palabra": New Forms of Leadership Between Guarani Women from Northwest Argentina}

\begin{abstract}
From the 90's onwards, Guarani women from Northwest Argentina began to demand a bigger participation in their communities, as well as within indigenous organizations. Beyond the fact that some women have managed to attain the recognition of their people by assuming different positions of leadership, truth is, this is a process of change that faces strong resistance and criticism from the indigenous organization spaces that, traditionally, have been male spaces. This leads us to explore the roles assigned to women within the Guarani people. Taking an ethno-historical and ethnographical point of view, our purpose is to be able to account for certain transformations in the gender relationships that have made possible for indigenous women to exercise their right to participate in the public life of their people. The modalities adopted by the leadership of Guarani women are analyzed through their own participation experiences as authorities in political community organizations and interethnic regional organizations.
\end{abstract}

Keywords: leadership; Guarani women; gender relationships; northwest Argentina; rights

\section{Lhe dando a palavra: novas modalidades de liderança entre mulheres guaranis do noroeste argentino}

\section{Resumo}

Desde a década de 1990 em diante as mulheres guaranis do noroeste argentino começaram a demandar maior participação no interior das suas comunidades assim como dentro das organizações indigenas. Além de que algumas mulheres tivessem conseguido reconhecimento dos seus povos assumindo diversas posições de liderança, o fato é que trata de um processo de mudança bastante resistido e questionado desde os espaços de organização indígena que, tradicionalmente, são espaços masculinos. Isso nos leva a explorar os papeis atribuídos às mulheres no seio do povo Guarani. Através da adopção de um olhar etno-histórico e etnográfico, nossa intenção é de poder dar conta de algumas transformações nos relacionamentos de gênero que fizeram possivel que mulheres indígenas estivessem exercendo seu direito a participar da vida pública dos seus povos. As modalidades que a liderança das mulheres guaranis assume analisam-se através das próprias experiências de participação delas como autoridades em organizações politicas comunitárias e organizações inter-étnicas regionais.

Palavras-chave: liderança; mulheres guaranis; relações de gênero; direitos; noroeste argentino 


\section{Introducción}

Desde las declaraciones y reconocimiento público del Ejército Zapatista de Liberación Nacional acerca de los derechos particulares de las mujeres indígenas, son muchas las mujeres latinoamericanas que -haciéndose eco de estos postulados y en un contexto global caracterizado por la expansión del discurso de los derechos- han comenzado a reclamar al interior de sus pueblos una mayor participación política, entendida como aquella implicada en las deliberaciones, negociaciones y procesos de toma de decisiones referidas a la vida colectiva que afectan a los grupos (Segato, 2003).

El impacto del movimiento zapatista y de otras experiencias que se estaban dando en organizaciones indígenas en Ecuador que reconocían públicamente a las mujeres, colocó en el centro del debate un aspecto hasta ese entonces relegado dentro de las agendas de los pueblos: que en la lucha por los derechos colectivos las voces de las mujeres indígenas habian sido, en gran medida, silenciadas. Pues si bien desde 1970 los movimientos indígenas latinoamericanos habían comenzado a conseguir sus primeros logros (recuperación de tierras, reconocimiento de derechos civiles y étnicos, conquista de espacios políticos, etc.), no había en ellos un posicionamiento específico sobre género, la agenda de las mujeres era minimizada y su participación reducida dentro de los movimientos (Ulloa, 2007; Pequeño, 2009). De ahí que esta coyuntura histórica particular -en paralelo a lo que un conjunto de organismos internacionales definió como la década de la Mujer $^{4}$ - abriera la posibilidad para que mujeres indígenas en distintos países latinoamericanos comenzaran a reflexionar acerca de su situación específica como mujeres y a debatir aquellas prácticas tradicionales de sus pueblos que iban en contra de sus derechos individuales y su dignidad. Muy pronto, el discurso de los derechos de las mujeres se convirtió en la fórmula privilegiada que tanto mujeres indígenas como agencias y organizaciones no gubernamentales (ONGs) adoptaron para referirse a una diversidad de experiencias que ponían de relieve su papel subordinado, así como también su invisibilización en la historia y las luchas protagonizadas por los pueblos indígenas.

Esta década (1976-1985) -denominada así a partir de Naciones Unidas- dio lugar a un ciclo de conferencias internacionales sobre la Mujer. En el marco de estas conferencias se crea el instrumento más completo para la promoción de los derechos de las mujeres: la Convención sobre la Eliminación de Todas las Formas de Discriminación contra la Mujer (conocida por su sigla en inglés CEDAW). Ver Cunningham (2003) y Cabezas Gonzales (2012) acerca de la importancia de estos procesos de articulación y conformación de espacios propios para las mujeres indigenas. 
Sin embargo, el lenguaje de los derechos no solo les ofreció un marco desde el cual analizar su posición y valor como mujeres indígenas, sino además la posibilidad de proyectarse hacia el futuro. En ese sentido, se trata de un discurso contenedor de una heterogeneidad de temáticas, experiencias y voces orientadas tanto a revisar aquellas normas culturales (referidas también como costumbres) en detrimento de la autonomía de las mujeres, como a impulsar cambios dentro de sus hogares, comunidades y organizaciones en pos de ser reconocidas y de que sus palabras sean escuchadas.

Bonfil Sánchez (2003) sostiene, refiriéndose al caso mexicano, que "conquistar el derecho a decir su palabra" es uno de los principales desafios que enfrentan los liderazgos de las mujeres indígenas (p.6). Coincidimos aquí con lo señalado por esta autora con respecto a que no es posible entender las críticas de las mujeres indígenas a la falta de espacios comunitarios para construir y decir su palabra como un proceso homogéneo; sin embargo sí es posible caracterizarlo como un elemento de redefinición de los grupos de poder dentro de las comunidades y organizaciones indigenas. Mucho se ha dicho acerca de los obstáculos que las mujeres tuvieron que enfrentar por parte de sus compañeros que no dudaron en tildar sus demandas como ajenas y de buscar socavar al movimiento indígena. Frente a estas acusaciones algunas mujeres salieron a explicar que su intención era caminar junto a sus pueblos, pero que para alcanzar la autonomía de las mujeres era necesario dejar atrás ciertas normas consuetudinarias que las subordinaban (como por ejemplo los arreglos matrimoniales) y que se dieran transformaciones en las relaciones desiguales de poder entre los géneros.

Las demandas que impulsaron las mujeres fueron de distinto tenor, pero sin lugar a duda, su participación adquirió gran relevancia. Si hasta ese momento, las mujeres indígenas habian sido -en una gran mayoría de casos- excluidas de los espacios de toma de decisiones (comunales y organizacionales), a través de este reclamo comenzaron a disputar estos espacios. Es el caso, por ejemplo, de lideresas de países como México y Guatemala que han cuestionado aquellas prácticas culturales que violentan a las mujeres sirviendo además como pretexto para negarles, entre otros derechos, su participación política (Méndez Torres, 2009; Bonfil Sánchez, 2003; Valladares y Pérez Cárdenas, 2010). En palabras de Martha Sánchez (2012), una dirigente indigena guerrerense, que luego de superar una serie de obstáculos, logró ser reconocida y ejercer un liderazgo en diversos ámbitos: 
Lo que queremos conseguir con nuestra lucha lo traemos muy interiorizado. No estamos por un proyecto ocasional o un financiamiento, sino por la convicción de sumar esfuerzos, como mujeres indigenas, a la lucha histórica de los pueblos. A esa lucha no nos queremos sumar invisibles; porque sé que hubo mujeres heroínas en el pasado, pero no se escribieron o rescataron sus historias. Nosotras hemos decidido ser visibles, mujeres sujetas de derechos y luchando por los derechos de sus pueblos. (pp. 264-265)

Estos procesos de organización e incidencia política no son iguales en todos lados; los contextos juegan un papel importante en las posibilidades que tienen las mujeres indigenas para impulsar sus reivindicaciones y su participación, dentro y fuera de sus pueblos. En el contexto argentino, aún son muy pocas las mujeres indigenas del noroeste que han logrado asumir posiciones de autoridad y representatividad dentro de sus pueblos y organizaciones ${ }^{5}$. En el caso de las mujeres guaranies lo que se observa es que si bien algunas están logrando asumir estos roles, se trata de un proceso de cambio fuertemente resistido y cuestionado desde los espacios comunitarios y de organización indigena. Los obstáculos y resistencias a los cuales se enfrentan estas mujeres son muy grandes y se relacionan con el peso relativo de la presencia y poca capacidad de incidencia política del pueblo Guaraní en el ámbito político local no indígena.

En la actualidad, y no en todos los municipios ni departamentos de la provincia de Salta, existe la figura del director de la Secretaría de Pueblos Originarios, un cargo dependiente y en ocasiones además condicionado, por la estructura politica partidaria del gobierno municipal. Una situación bastante similar es la que se evidencia a nivel provincial para el caso de los funcionarios indigenas del Instituto Provincial Indigena de Salta (IPPIS) y a nivel nacional, en aquellos funcionarios que se desempeñan como delegados del Consejo de Participación Indígena del Instituto Nacional de Asuntos Indigenas.

La delegación de Salta del Foro Nacional de Agricultura Familiar de la Subsecretaría de Agricultura Familiar, perteneciente al Ministerio de Agricultura, Ganadería y Pesca de la Nación -que en sus inicios se planteó como un espacio organizativo a nivel provincial donde confluyen organizaciones indigenas, campesinas y funcionarios- dio un giró en estos últimos años, cobrando en él supremacía de un discurso político partidario. En este sentido, tanto a nivel municipal como provincial

\footnotetext{
5 Ver, sin embargo, los casos de las lideresas kollas Rosario Quispe y Natalia Sarapura (VV. AA. 2007) y de Mónica Romero para el caso guaraní (Gordillo, 2010).
} 
existen limitados espacios de participación indígena y en particular de incidencia política del pueblo Guaraní.

En una conversación con Francisca Mendoza ${ }^{6}$, mburuvicha ${ }^{7}$ de Peña Morada, comunidad indígena de la localidad de Aguaray, Departamento San Martín, provincia de Salta -que para ese entonces ya llevaba más de siete años como máxima autoridad de su comunidad- habló de las dificultades que enfrentaba de la siguiente manera:

En junio del año pasado participé de la Red de Comunicación Indígena, una reunión que organizaron varios caciques del Departamento. Eran todos hombres. Yo estaba sola para discutir con los hombres. Algunos me decían: "Los wichí [pueblo indígena] te van a pegar".

Conversamos un buen rato sobre lo que había sucedido en la reunión, pero lo que más me llamó la atención fue que en repetidas oportunidades, Francisca utilizó el término discriminación para referirse a cómo se sentía frente al trato que las mujeres recibian por parte de muchos caciques que a su vez, integraban las organizaciones. Sin embargo, esto no era lo único que surgía de su relato, pues ella también mencionaba que su presencia era percibida por los hombres como una amenaza y que la violencia física era entendida como un mecanismo de control sobre su participación. Pero si esta era una de las fórmulas empleadas más recurrentemente por algunos caciques para desalentar la participación de las mujeres indígenas, ello no significaba que la subjetividad de las mujeres indígenas y las relaciones entre los géneros no estuvieran cambiando. De hecho, ella no perdia de vista que uno de los caciques de una comunidad vecina le había brindado todo su apoyo cuando asumió como líder comunitaria. Lo que Francisca les contestó a los caciques en aquella reunión ilustra estas transformaciones que se vienen dando al interior de los pueblos indígenas:

Quiero ver quién se anima a pegarme. Yo les dije que las mujeres se han valorizado, que no son como antes y que debían darles más participación. Que las mujeres han perdido el miedo y que se sienten capaces de hacer algo. Antes creíamos que nos podía pasar algo, pero con lo que vamos consiguiendo y aprendiendo a valorizarnos como que nos sentimos con más fuerza. Ya no es como antes.

6 Todos los nombres propios de las personas que figuran en el trabajo cuentan con su debida autorización o fueron modificados.

7 En guaraní significa cacique. 
En las palabras de la mburuvicha se reconocen una cantidad de mujeres guaranies de distintas generaciones que al igual que ella, ponen de relieve los cambios que se están dando por un lado, a nivel de la subjetividad de las mujeres, lo que supone -entre otras cuestionesinterpelar los roles que les han sido tradicionalmente asignados dentro de su pueblo. Por el otro, las transformaciones en el plano de las relaciones de género que han hecho posible que mujeres indígenas estén ejerciendo su derecho a participar como autoridades en la vida pública de sus pueblos. Lo anteriormente señalado, nos lleva a adoptar una perspectiva etnohistórica que se suma al trabajo de campo realizado en comunidades indígenas rurales del Departamento San Martín para explorar cuáles han sido las relaciones de género y los papeles tradicionalmente desempeñados por las mujeres dentro de sus comunidades.

A través de este enfoque, nuestra intención es poder dar cuenta de cómo es que mujeres guaraníes llegan a asumir diversas posiciones de liderazgo, así como recuperar el sentido y valor que ellas le otorgan a estas experiencias de participación como autoridades dentro de sus organizaciones políticas comunitarias y sus organizaciones interétnicas regionales, y el papel que juega en ellas el discurso de los derechos de las mujeres. En este sentido, podemos destacar el rol central que tuvieron las organizaciones zonales de desarrollo en la producción de este lenguaje de derechos que las mujeres se han ido apropiando en instancias organizativas como los talleres, capacitaciones y encuentros de mujeres indígenas.

Las alianzas que estas mujeres han trabado con ONGs y agentes de desarrollo -especialmente de la sociedad civil- es un factor de peso en lo que respecta a la construcción y apropiación de un discurso propio de derechos y a los procesos de participación politica que disputan y protagonizan. Estas alianzas estratégicas entre mujeres indigenas, la sociedad civil organizada y agentes de desarrollo, han sido reconocidas como muy significativas en lo que respecta al desarrollo de los liderazgos y su discurso de derechos.

\section{De las normas tradicionales a los derechos de las mujeres}

Ahí fue cuando nos dimos cuenta de que teníamos derechos y que no solo debiamos cuidar a los chicos y estar en la casa. También tenemos derecho a salir, a divertirnos. (Susana Alcoba, comunidad Capiazuty) 
Para muchas mujeres guaraníes del noroeste argentino, el discurso de los derechos que empezó a circular en la década de 1990 a través de políticas de desarrollo y organizaciones de la sociedad civil significó por un lado, tomar conocimiento acerca de un cuerpo normativo jurídico y por el otro, llevar adelante una reflexión acerca de su papel, estatus, relaciones de género y la división sexual del trabajo. Como había sucedido en otras partes de América Latina, hasta ese momento la formación en derechos indigenas había estado principalmente dirigida a aquellos hombres que se desempeñaban como autoridades de sus comunidades o dentro de organizaciones. Las mujeres indígenas que habian asistido por primera vez a una capacitación en derechos brindada por las técnicas de un programa de desarrollo rural, recordaron el impacto que esto generó en ellas:

Antes nosotras estábamos desinformadas y ahora no lo estamos, por la participación. Antes, cuando había capacitaciones sobre derechos, la mayoría era para hombres y caciques.(Nora López)

A través de las capacitaciones que se dieron en sus propias comunidades, las mujeres guaranies empezaron a formarse en los derechos que les corresponden como mujeres y como indígenas. El trabajo que encararon junto a las técnicas ${ }^{8}$, consistió en tomar conocimiento acerca de las distintas herramientas jurídicas que disponen los pueblos indigenas para hacer valer sus derechos, como así también familiarizarse con aquellas normas que hicieran referencia a su condición como mujeres. Así, paralelamente al análisis que hicieron de la reforma Constitucional Nacional ${ }^{9}$ de 1994 que reconoce la preexistencia étnica y cultural de los pueblos indígenas argentinos, de la constitución provincial salteña ${ }^{10}$-parcialmente reformada en 1998- y del Convenio número 169 de la Organización Internacional del Trabajo ${ }^{11}$, realizaron una lectura de normas y leyes orientadas a garantizar sus derechos como mujeres. Conocer sus derechos, como me dijeron varias mujeres guaranies, está vinculado con "hacerse respetar", contar con una "herramienta de defensa", tener un mayor control sobre sus vidas, promover

\footnotetext{
8 Trabajan en programas de desarrollo y en 2002, crearon su propia fundación: la Asociación Regional de Trabajadores en Desarrollo (ARETEDE). Las principales destinatarias de sus acciones han sido mujeres indígenas del Departamento San Martín.

9 Ver Artículo 75, inciso 17.

10 Ver Artículo 15, contradicción entre el inciso I y II.

${ }^{11}$ El Estado Argentino es signatario de este Convenio en el 03/07/2000.
} 
relaciones de género más equitativas y también, con ser reconocidas por el Estado como sujetos de pleno derecho. En sus propias palabras:

Es importante el respeto, que vos te hagas respetar como mujer. Es el respeto que vos tengas del hombre. Una mujer se tiene que hacer respetar. Si el hombre también se hace respetar por la mujer. Calumnias te pueden poner montones, pero la vida es tuya. (Entrevista a Soledad Félix, Campo Blanco, 22 de agosto de 2005)

La capacitación es en los derechos que tenemos como mujer frente a los de arriba, ante el gobierno. Tenemos derecho a salir, a pedir, a agruparnos, a trabajar y a educarnos. Y en la casa se ha enseñado que si bien la mujer es sometida, a todas las mujeres les pasa lo del sometimiento, a la mujer se la capacita a sobresalir, a hacer valorar nuestros derechos en la casa. Pero nadie viene del grupo de mujeres a pelear en la casa... Para eso hay jueces, abogados, hay autoridades que nos pueden ayudar a nosotras como mujeres. En los encuentros les han enseñado a ser así, dicen los hombres, "Que no me tengo que dejar pisotear por nadie, ni por el intendente”. Todas esas capacitaciones ha habido acá. Nosotras tenemos que buscar la igualdad. No pisotear al otro. Si yo hubiese sabido el valor de ser mujer y él también [refiriéndose a su marido], yo no hubiese sufrido. (Ester Santos, Peña Morada, 4 de noviembre de 2005)

Nosotros decimos que no queremos que la mujer se ponga sobre el hombre. Algunos hombres creen que la mujer quiere estar por sobre el marido, pero lo que queremos es la igualdad entre el hombre y la mujer. Queremos que él salga a divertirse y la mujer también. No que él salga y la mujer esté en la casa, cuidando a los hijos. (Nora López, en su casa, Aguaray, 13 de febrero 2010)

Las mujeres guaraníes que se vincularon con agentes de desarrollo y organizaciones de la sociedad civil que jugaron un papel central en la construcción y apropiación de su discurso de derechos, viven en comunidades rurales y peri urbanas, en los municipios de Salvador Mazza, Aguaray y Tartagal, en el Departamento Gral. San Martín. Se trata de comunidades que en un contexto de agudo desempleo combinan con prácticas agrícolas -en menor medida la caza y pesca- y según la época del año, con trabajos informales (peones, changarines, empleadas domésticas) y con diversos recursos provenientes de programas de desarrollo y subsidios sociales para cubrir sus necesidades básicas. 
Muchas de estas mujeres indígenas no contaban con estudios primarios completos. Pocas y fundamentalmente la generación más joven, habían abandonado a nivel secundario. En sus estudios formales como no formales adquiridos en el seno familiar, el aprendizaje de la historia indígena regional como el idioma -expresión utilizada para referirse a la lengua guaraní-, ocupaban un lugar marginal. Estas mujeres guaraníes tampoco contaban con una fuente de ingreso económico ni tenian garantizada una adecuada atención en los centros públicos de salud, lo cual se evidencia en la imposición de conocimientos y prácticas médicas (cesáreas, ligadura de trompas, etc.) o culpabilización y abandono de las mujeres ante casos de abortos. A esto se suma que una gran mayoría de estas mujeres viven en comunidades que no tienen títulos sobre sus tierras y que ello les genera un sinfin de problemas cotidianos (y en muchos casos conlleva una judicialización de los casos y criminalización de la protesta), en tanto se hallan expuestas a que tanto particulares, empresas o el mismo Estado, las expulsen o desalojen de sus tierras.

Ahora bien, en la Convención sobre la Eliminación de todas las formas de Discriminación contra la Mujer, las mujeres guaranies encontraron una referencia a la condición de mujer rural que siendo lo suficientemente amplia como categoría, ofrecía una enumeración de derechos que les permitía englobar los propios. De esa enumeración, ellas recuperaron principalmente el hecho de que a las mujeres rurales se les reconocía el derecho a la atención médica y a la planificación familiar; a obtener todos los tipos de educación y de formación (alfabetización, capacitación, etc.) y a participar en todas las actividades comunitarias. El hecho de que estos derechos no siempre se cumplieran fue el sustrato para reflexionar sobre las situaciones cotidianas de discriminación que vivian (y viven), identificar una serie de problemáticas que les eran comunes, en tanto mujeres indígenas y tomar conciencia acerca de la importancia de que su palabra comenzara a ser escuchada.

En esa dirección, uno de los primeros pasos que dieron las mujeres fue salir de la casa. Esto conllevó un desafio, en tanto suponía desatender tareas vistas como una responsabilidad exclusivamente femenina (cuidar los hijos y realizar los quehaceres domésticos) y contestar el papel socialmente asignado para ellas. Las fuentes históricas, como es el caso de la obra redactada por el misionero franciscano Gianecchini (1996/1898) ponen especial atención sobre la formación que las niñas chiriguanas ${ }^{12}$ recibian por parte de otras mujeres de su hogar:

${ }_{12}$ En la literatura etnohistórica se conoce a los guaranies con el nombre de chiriguano (Saignes, 
Las niñas siempre al lado de sus madres, tías o abuelas, haciendo todo lo que ven que ellas hacen, cuidando a los niños más pequeños, y según van creciendo ya comienzan a ayudar en los quehaceres domésticos [...]. (p. 343)

Este franciscano, sin embargo, no fue el único en observar que en la división sexual del trabajo, a las mujeres les tocaba desempeñarse fundamentalmente en la esfera doméstica, encontrándose las prácticas de maternidad también vinculadas a este espacio ${ }^{13}$. El padre De Nino (1912), que vivió más de veinte años en una reducción chiriguana a finales del siglo XIX y principios del XX en Bolivia, también registró en su diario que la mujer era "el carguero de la casa", ya que se ocupaba de acarrear el maíz, traer agua desde largas distancias, preparar la comida, elaborar la chicha, criar gallinas y chanchos, tejer e hilar y cuidar a sus hijos, entre otras tareas (p. 208).

No todos los aprendizajes sin embargo, estaban orientados a la realización de tareas domésticas. De hecho un aspecto central de la educación de las niñas y mujeres guaraníes en el siglo pasado, tenía que ver con que las ancianas -que detentaban mayor prestigio y respeto- les transmitieran oralmente a las jóvenes una serie de saberes y normas considerados constitutivos de la personalidad de la mujer. Sus lecciones incluían ideas de obediencia, sumisión y dependencia hacia los hombres, puesto que ellos eran percibidos teniendo una autoridad absoluta sobre la mujer.

Gianecchini anotó que una abuela le diría a una joven: "Mira, hija, nosotras solo queremos mujeres nacidas y hechas para el placer de los hombres, para servirles y depender de ellos en todo, puesto que son nuestros señores, para darles hijos y cuidar de ellos", (1996/1898, p. 343). Si algunas prácticas como los matrimonios arreglados que daban cuenta de la posición desigual de las mujeres en el pueblo Guaraní, han ido cambiando en los últimos cincuenta o sesenta años, otras formas de relación de poder aprendidas y culturalmente toleradas en cambio -como los celos, la infidelidad, la violencia física y su condición de esclava-, encuentran eco entre los reclamos que ellas impulsan en el presente. A esto se refirió Nora López durante una conversación que mantuvimos:

2007/1982). El término guaraní engloba a los subgrupos ava, isoseño, simba que comparten la lengua, pero que tienen sus especificidades históricas y locales. Optamos por el término guaraní ya que es como se identifican las personas en la zona.

${ }^{13}$ Hirsch (2008) plantea que la feminidad se define a través de la maternidad y que su valor estaría dado a partir de su condición reproductora, siendo la cantidad de hijos un factor importante en el estatus que adquiere la mujer dentro de su familia. 
Hay muchas mujeres golpeadas y marginadas por los hombres, muchas mujeres que están sometidas a los hombres, que les dan todo en la casa. Ellas creen que deben ser esclavas. Para mí no deben esclavizarse. Una también puede ser libre. Hombres y mujeres tienen que tener la misma libertad, llevar la casa juntos, mandar los dos en el hogar y no solo el hombre. (Campo Blanco, 22 de agosto de 2005)

Para Nora López de 45 años como para otras mujeres que asistieron a las capacitaciones, el discurso sobre los derechos se convirtió en una herramienta para cuestionar un estereotipo de mujer guaraní, las relaciones desiguales entre los géneros y la violencia doméstica ${ }^{14}$. Esas mismas reflexiones -como surge de su testimonio- brindaron pistas para repensar nuevos modelos y formas de relacionarse entre los géneros. Este es el tipo de apropiación que algunas mujeres han hecho de los conocimientos que circularon en capacitaciones en las que realizaron una lectura de la Declaración sobre la Eliminación de la Violencia contra la Mujer para analizar sus respectivos contextos y luego poder proyectar una vida libre de violencia.

Para otras mujeres -tal como me dijo una de mis interlocutoras-, conocer esta normativa fue el primer paso para luego informarse sobre los posibles caminos a seguir en caso de maltrato (incluyendo en este término la violencia física, psicológica y sexual), cuando quieren separarse o cuando son abandonadas por sus maridos, quedando ellas a cargo de los hijos. Lo anterior permite entrever que las mujeres le fueron dando distintos sentidos a los conocimientos de acuerdo a sus propias experiencias personales.

Si como ya señalamos, uno de los primeros pasos en la toma de conciencia consistió en analizar cómo se encontraban posicionadas al interior de sus hogares y comunidad, a esto le siguió un trabajo orientado a valorizar su identidad, su papel dentro de la sociedad guaraní

${ }^{14}$ En este sentido no deja de sorprender la entrevista realizada a Hirsch y publicada por la Agencia de noticias Redaf el 5 de julio de 2011, en donde la antropóloga afirma que existe "una situación bastante equitativa entre los hombres y las mujeres, un gran respeto a la mujer como tal y a la función materna. No estoy negando que haya violencia y desigualdades. Pero hay grupos alejados en los cuales casi no hay violencia de género". La situación "bastante equitativa" de la que habla Hirsch no se corresponde en absoluto con la percepción y experiencias cotidianas que viven las mujeres de la zona como también es muy cuestionable la idea de que hay "grupos alejados" (lo cual descansa en una supuesta pureza o no contaminación vinculada al otro, a lo no indigena) y de que la "violencia de género" es un fenómeno externo a los pueblos indígenas. O como sostuvo la misma autora en otra entrevista "que hay muy baja incidencia de violencia sexual entre indigenas" (Página 12, 2011), cuando existen situaciones de abuso registradas por las propias mujeres en sus comunidades. Esta mirada invisibiliza los reclamos que las mujeres indigenas vienen haciendo en torno a las situaciones de violencia doméstica y de género en pos de alcanzar relaciones más equitativas. 
y algunos roles tradicionales que en muchas comunidades, se han ido dejando de lado como por ejemplo, el de cuña ipaye (curanderas) y parteras. La idea de rescatar estas figuras cobró aún más sentido cuando se analizó que ellas podrían jugar un papel fundamental como traductoras e intermediarias con el sistema médico hospitalario y así reducir la morbimortalidad materno-infantil que afecta principalmente a las comunidades alejadas donde las madres concurren poco a los centros de atención por razones económicas, geográficas y culturales.

En ese acto particular de proponer recuperar y valorizar estas figuras, las mujeres estaban poniendo de relieve no solo aquellos aspectos que las afectan en su condición de género, sino muchos otros vinculados a las condiciones de desigualdad, marginación y discriminación en la que se encuentran inmersas como integrantes de pueblos indigenas.

Existe un amplio debate en torno a las relaciones complementarias o de exclusión en las relaciones de género en los pueblos indígenas mesoamericanos, andinos y sudamericanos ${ }^{15}$. Si bien nuestra intención aquí no es recuperar las diversas posiciones que los estudiosos han tomado frente al tema, lo que sí nos interesa revisar es el modelo de Boserup (1970) -con respecto a que una mayor participación económica de las mujeres traería aparejada un mayor acceso al poder político o a la toma de decisiones- para dejar al descubierto sus límites al analizar las posiciones que ocupan las mujeres guaraníes.

La misma Hirsch (2003), que ha retomado este enfoque y no duda en afirmar que existe una complementariedad jerárquica entre los géneros, se encuentra con restricciones cuando intenta responder a la pregunta de por qué la alta participación económica de las mujeres guaranies no se tradujo en una mayor participación política. La idea de una supuesta desigualdad entre los géneros basada en que las mujeres realizan una menor contribución a la economía doméstica no ha sido un tema de preocupación para ellas. Ni tampoco es posible sostener la tajante división que ha permeado los debates feministas ${ }^{16}$ acerca de que a las mujeres indígenas se les asigna el espacio doméstico mientras que los hombres ocupan el espacio público y político. En un contexto en el que las mujeres tienen gran protagonismo en la comercialización de su producción agrícola a través de la venta en mercados, ferias y

\footnotetext{
${ }^{15}$ Ver Hernández y Canessa (2012), Perrin y Perruchon (1997) y Pequeño (2009).

16 Overing (1986) y Kidd (1995) cuestionan la existencia de una esfera de lo politico escindida del resto de las actividades de la vida social y la idea de que lo politico sea universalmente la esfera más valorada. Ver Hernández (2001) acerca del feminismo indígena y sus críticas tanto al sexismo y esencialismo de las organizaciones indígenas como al etnocentrismo hegemónico asociado a la academia.
} 
negocios de pueblos, mantener esta clasificación dicotómica no aporta demasiado para explicar cómo es que mujeres que desempeñan un rol económico tan activo en este ámbito de la vida social no conlleva necesariamente a que jueguen un papel central en la toma de decisiones y como autoridades comunitarias.

\section{La participación comunitaria: asambleas, consejos y mburuvichas}

"Ahora se le da más la palabra a la mujer, pero antes no era así", me dijo una de mis interlocutoras relacionando este nuevo escenario con el apoyo que a través de diversas iniciativas, las mujeres estaban recibiendo de actores vinculados al ámbito de las políticas de desarrollo y ONGs. Su comunidad lleva más de quince años con una mburuvicha como parte de un grupo de mujeres que asumieron como máximas autoridades del consejo comunitario, la forma de autogobierno gestada a partir de las reformas legales que supusieron un reconocimiento por parte del Estado. Esa comunidad rural guaraní es una de varias en donde las mujeres están incidiendo en la toma de decisiones dentro de las asambleas -donde se practica el consenso y la búsqueda de acuerdos, y cuya máxima autoridad es la voz del pueblo- y ocupando cargos como autoridades desde el ejercicio de sus propias prácticas de gobierno.

Así, si es posible encontrar que varias mujeres se están desempeñando al interior de sus comunidades -ocupando dentro del consejo y según el estatuto el rol de mburuvicha, presidenta, tesorera y secretaria- son unas pocas las que están empezando a disputar espacios extra comunitarios, como por ejemplo dentro del IPPIS. A estos cambios que se estaban dando y que generaban nuevas modalidades de liderazgo se refirió Francisca de la siguiente manera:

Los hombres no saben cómo ni qué es lo que hace falta dentro de la comunidad. Ellos solo piensan en lo más prioritario. En cambio, nosotras pensamos en cómo podemos ir proyectando para ir mejorando de a poco. Ellos quieren grandes cosas [...] Nosotras somos más y, además, tenemos esa paciencia de esperar. Ellos no tienen paciencia. Nosotras somos incansables [...] En Ferro [comunidad indígena, que al igual que La Bendición, La Pista y Obraje están ubicadas en el municipio de Salvador Mazza] está Balbina Segundo y en La Bendición, está Eulalia. Son dos mujeres que asumieron como caciques. La Eulalia dice que el padre era cacique en La Pista. Tiempo después, ella volvió a recuperar su comunidad: La Bendición. 
Porque no hace mucho tiempo que está ahí, hace dos años. Una vez, fuimos juntas a la oficina de tierra fiscal y a ella le dijeron que desconocian su comunidad porque era nueva. Pero ahora ya fueron a ver qué sucede. El otro día, en un encuentro del que participé, se presentó otra mujer como cacique de Obraje. Se llama Irene, pero es muy viejita. Antes no había mujeres cacique, pero ahora son la mayoria. (6/11/2005)

Entre los guaranies el liderazgo ha sido una práctica tradicionalmente vinculada a un rol masculino: el de mburuvicha. Por lo general, se trataba de hombres que gozaban de gran reconocimiento y prestigio basados en su saber acerca de la tradición, el pasado y la memoria; su capacidad o don de oratoria y valentía frente a los pueblos enemigos contra los que luchaban. Estas cualidades hacian que un jefe chiriguano pudiera aspirar a ser un gran hombre, un kereimba (guerrero), un ñeeiya (dueño de las palabras) o un arakuaiya (dueño de la sabiduría) (Villar y Bossert, 2008).

Nordenskiöld (2002/1912) señala que las familias de los jefes chiriguanos formaban una especie de "aristocracia" (p. 212), jugando la sucesión hereditaria un papel fundamental. Es decir que si el cacique fallecía este era sucedido por su hijo varón mayor y en el caso de que esto no fuera posible era el pariente hombre más cercano quien tomaba su lugar: tío, sobrino, nieto, yerno. En ausencia de estos posibles sucesores, se podía recurrir al pueblo en busca de alguna persona cuyo prestigio y fortuna estuvieran relacionados con un estatus económico alto. En el ejercicio de las tareas vinculadas a su cargo -administrar justicia, impulsar y coordinar el trabajo agrícola, organizar el arete $^{17} \mathrm{y} / \mathrm{o}$ comandar la guerra- los líderes recibían el apoyo de consejeros y ayudantes que -tal como su nombre lo indicaeran vistos como personas de gran sabiduría y guías en la definición del rumbo de sus comunidades y pueblos. A veces eran asistidos por un consejo de chamanes y ancianos eminentes, aunque también los asesoraban brujos y hombres que recibían el título de dueño del palo o del bastón, siendo estos últimos conocidos fundamentalmente con el nombre de alcaldes (De Nino, 1912). Como puede colegirse, se trataba de construcciones patriarcales en las que el lugar de las mujeres era secundario. Por si quedan dudas de que las mujeres guaraníes no eran tenidas en consideración, a continuación coloco dos citas en donde -en el primer caso un franciscano y en el segundo un

17 El arete es una celebración anual muy importante para el pueblo guaraní que se realiza entre febrero y marzo en agradecimiento a la cosecha de maíz. 
etnógrafo-, registran el hecho de que ellas raramente lograban acceder a posiciones de liderazgo:

Pocas y muy raras veces acontece que la viuda, la hermana o la hija tubicha, tengan que gobernar y dirigir la tribu, porque para ellos -como ya lo hemos dicho- la mujer es un uicoipochivaé, un cero a la izquierda. (Gianecchini, 1996/1898, p. 302)

Si es de presumir que las mujeres chiriguanas desempeñan cierta influencia en la vida social, raras veces acceden a la dignidad de tubisa (regional) o de cacique. Ningún obstáculo de principio, se opone, sin embargo, a su elección [...]. (Métraux, 1935, p. 419)

El humanismo en la mirada sobre la naturaleza indígena declarado de Métraux le impide ver que el mayor obstáculo para la inclusión de las mujeres se encuentra en las normas y tradiciones culturales de su pueblo. Un ejemplo de ello es la poligamia, una estrategia matrimonial a través de la cual las mujeres eran forzadas a contraer matrimonio y entregar su fuerza de trabajo en pos de que los caciques en cuestión reforzaran o mantuvieran su poder por medio de su generosidad en los convites de chicha (yo corregiría: de la generosidad de sus esposas). Dicho en otras palabras, las mujeres eran vistas como parte de un sistema de intercambio orientado a expandir o contraer -según la coyuntura- los lazos de alianza en busca de ventajas políticas.

Sin vincular ambos aspectos, el de la ausencia de mujeres como autoridades politicas comunitarias y las tradiciones desventajosas para ellas, Métraux describe que los jefes, con frecuencia hombres de edad, podian tener las mujeres que desearan: "Tanto más fácil era para los jefes contraer enlaces a su antojo cuanto que ninguna mujer podía rehusarse cuando le pedían matrimonio" (1935). Como me contaron varias de mis entrevistadas, los caciques no solo tenían mujeres en su pueblo, sino además en las aldeas vecinas dentro de su jurisdicción. Alguna recordó el sufrimiento que esto produjo en su madre, que era abandonada durante largos períodos de tiempo por su marido que se ausentaba de la casa para ocuparse de sus otras mujeres. Otra entrevistada en cambio, recordó la relación jerárquica a la que debían someterse las mujeres jóvenes cuando ingresaban como esposas de un jefe, ya que pasaban a quedar a cargo de la mujer de más edad, teniendo que obedecerle. 
La etnografia chaqueña (Nordenskiöld, 2002/1912; Métraux, 1948; Susnik 1968; Braunstein, 1983/1978; Hirsch 1991) ha trazado una imagen canónica del cacicazgo chiriguano apoyada en la idea de jefes sin poder y asambleas democráticas, un enfoque que tiene sus orígenes en el modelo clastreano (Clastres, 1974) acerca de la sociedad contra el Estado. En otras palabras, existe el supuesto de que gran parte de las sociedades amerindias se distinguen por su sentido de democracia y su gusto por la igualdad. Si bien no busco aquí debatir si efectivamente existieron jefes sin poder o si la asamblea era la sede máxima de autoridad, lo que sí me interesa destacar es el común acuerdo de un sinnúmero de estudiosos sobre los guaraníes con respecto a los valores de libre iniciativa y de igualdad en las relaciones políticas que contrastaban con la posibilidad de que un líder o chamán pudiera hacer uso de la fuerza simbólica provista por su envestidura para obligar a alguien a hacer algo si no lo deseaba (excepto en tiempo de guerra) (Combès y Villar, 2004).

A principios de siglo XX, cuando el misionero franciscano De Nino convivió con los chiriguanos, es muy probable por sus observaciones que las relaciones con los hacendados o autoridades coloniales, karai (blanco en guaraní) y religiosos en las reducciones hubieran contribuido a acentuar el poder de los caciques; al mismo tiempo que el hecho de que intervinieran en su elección contribuyó a que estos muchas veces, debieran obedecer sus órdenes. Como consecuencia del proceso de transformaciones sociales y politicas (la vida en las misiones franciscanas; la Guerra del Chaco entre Bolivia y Paraguay entre 1932 y 1935; el trabajo en los ingenios azucareros, entre otros.) que atravesó el pueblo guaraní, la figura de los líderes también se deterioró. Más aún, lo que sucedió fue que con el tiempo, fueron surgiendo nuevos tipos de líderes: los impuestos por las autoridades religiosas; los apuntalados por los contratistas de los ingenios azucareros; los derivados de intensas movilizaciones y de su politización como sujetos de derecho y todos ellos pasaron a coexistir con los líderes tradicionales o hereditarios (Magrassi, 1968).

A esto se suma el protagonismo que vienen asumiendo algunas mujeres guaraníes como autoridades, un hecho que supuso una serie de cambios que mis interlocutoras asociaron en gran medida, con el estímulo que recibieron por parte de agentes vinculados al desarrollo. “¿Cómo podemos hacer para participar más?”, recordó una mujer que una de las técnicas de la zona con quien lleva más de quince años trabajando, había preguntado durante esas primeras reuniones que tuvieron. “¿Podemos asumir cargos en el consejo?”, me dijo que les 
había preguntado para luego afirmar lo que evidentemente, ella consideraba como un espacio a conquistar: "Es importante que las mujeres participen de la toma de decisiones, que participen del consejo y que nos animemos a hablar".

En este sentido, la presencia y actuación de las ONGs y los cambios en las politicas gubernamentales, agencias y programas de desarrollo que han incluido a las mujeres indígenas están modificando el modelo de liderazgo tradicional masculino. Aún cuando en ocasiones, tal como señala Kidd (1995), el liderazgo puede resultar un "puesto muy poco deseado", para las mujeres que como me dijeron, habian logrado comenzar a vencer su timidez, perder el miedo y la vergüenza a expresarse en público a través de la educación formal y las capacitaciones en derecho, este era un rol que aun así debian disputar en pos de que sus voces fueran escuchadas.

Los altos índices de desempleo ${ }^{18}$ que se dieron en el marco del avance de las políticas neoliberales que afectaron la zona jugaron un papel decisivo para que las mujeres fueran ganando reconocimiento dentro sus comunidades y con ello, que fueran asumiendo un papel más protagónico dentro de sus formas de organización. Así como muchos hombres vieron en la migración laboral temporal una respuesta -también temporal- a la falta de oportunidades locales, ellas que en muchos casos quedaron al frente de la economía familiar, aprovecharon este contexto para posicionarse politicamente dentro de sus comunidades. Durante una conversación que mantuvimos con Francisca sobre el momento en que asumió el liderazgo comunitario, ella me contó que su esposo no había podido ser líder porque se ausentaba constantemente de la comunidad; que a él no le gustaba que saliera y que eso lo violentaba; que cuando la eligieron en asamblea, el cacique anterior le habia cuestionado que una mujer tuviera capacidad de liderar, pero que ella había aprendido de su padre que ya había sido responsable de la comunidad (y además curandero). Luego continuó así:

Y nosotras, como mujeres, somos las que más estamos. No como los hombres que salen a trabajar afuera. Y por eso conocemos las necesidades de la comunidad: la escuela, los maestros, los chicos,

${ }^{8}$ En el Departamento San Martín “35,3\% de los hogares (40,7\% de las personas) tienen sus necesidades básicas insatisfechas (NBI)", siendo estos "indicadores muy superiores a la media provincial $(27,5 \%$ y $31,6 \%$, respectivamente"; $52,1 \%$ de la personas $(41,4 \%$ de los hogares) se encontraba en Salta por debajo de la línea de pobreza y casi un quinto de la población tenían ingresos por adulto equivalente inferiores a los necesarios para superar la línea de indigencia" (Deledicque, 2007, pp. 2-3). 
sabemos lo que necesitan, el comedor, las madres embarazadas y los abuelos, el agente sanitario, la vacunación y los enfermos, el problema del agua que no llega en verano y los títulos de tierra, hay gente que quiere entrar a la comunidad a sacar nuestros recursos y hay que defenderlos. De todas esas necesidades sabemos. (Francisca, 06/06/2005)

Este es el testimonio de Beatriz Caballero que se desempeñó como autoridad del consejo de la comunidad de Capiazuty:

Con los encuentros y capacitaciones cambió mucho la comunidad. Antes las mujeres no participaban en el consejo. Ahora la mayoría de los cargos los ocupan mujeres. También son la mayoría mujeres las que participan en asambleas. (31/08/2005)

El 28 de noviembre de 2008 durante una asamblea, Beatriz fue elegida, junto a otras doce mujeres de un total de dieciséis miembros del consejo, como autoridad comunitaria. Ella integró esta nueva comisión que a diferencia de las anteriores -según me dijo, constituidas por "personas mayores"- se conformó mayoritariamente por gente joven. Más allá de que las mujeres no siempre quedaran, como en este caso particular, al frente de sus comunidades, lo que se observa es que en este nuevo escenario, ellas fueron cobrando gran protagonismo en los distintos procesos de lucha y movilización de la zona, vinculados a la reivindicación de mejores condiciones de vida para sus comunidades y pueblos (lo cual abarca salud, educación, territorio, acceso a servicios básicos y poder de determinación sobre los proyectos de desarrollo que los afectan). Pues, si bien para las mujeres guaranies es importante obtener el reconocimiento de sus compañeros, no menos cierto es que sus reivindicaciones se enmarcan en un proyecto de vida más amplio, que es el de sus comunidades y pueblo.

Es interesante destacar que varias de las mujeres que asumieron posiciones de liderazgo en sus comunidades, como es el caso de Francisca, Susana y Nora, pertenecen a familias cacicales, siendo un rasgo de los chiriguano que estas familias formen una especie de aristocracia (Nordenkiöld, 2002, p.212). Esta misma situación se observa en el caso de México, donde hijas de líderes comunitarios de gran trayectoria han asumido posiciones de liderazgo dentro de sus comunidades (Romay Mendoza, 2012; Vianey Vargas, 2012). 


\section{Reflexiones finales}

Cada vez es más frecuente encontrar a mujeres guaraníes desempeñándose como autoridades comunitarias. Y si bien todavía no es posible generalizar su participación, lo cierto es que se trata de una tendencia en crecimiento en muchas partes del noroeste argentino. Los espacios de formación (capacitaciones, encuentros, viajes) y las organizaciones de mujeres -nucleadas en torno a diversos proyectoshan desempeñado un importante papel en este sentido, valorando el rol de la mujer en el hogar, la comunidad y dentro del pueblo Guaraní, promoviendo relaciones igualitarias entre los géneros y buscando una mayor presencia e involucramiento de las mujeres en la toma de decisiones y un reconocimiento en puestos de liderazgo.

En esta búsqueda por tornarse visibles y ser protagonistas de las luchas históricas que impulsan sus pueblos, las mujeres otorgaron especial valor a los conocimientos y formación política adquiridos a través de políticas gubernamentales, programas y agentes de desarrollo local como las ONGs -en particular al discurso de los derechos y a la reflexión sobre los roles y relaciones de género- en tanto en ellos encontraron un lenguaje poderoso desde el cual hacerse oír en un sinnúmero de situaciones en las que sus voces eran silenciadas por ser mujeres, por ser indigenas y por ser pobres. Así, para muchas de las mujeres guaranies incidir como autoridad y en la asamblea a través de la toma de decisiones, se convirtió en la posibilidad de manifestar y reclamar públicamente acerca del alcance y los límites en el ejercicio de sus derechos, tanto como mujeres, como indígenas y ciudadanas argentinas.

Es interesante notar que en paralelo a esta búsqueda de reconocimiento por parte de varias mujeres, lo que se construyó fue un paisaje de reivindicación de derechos, en el sentido de que se reelaboró un lenguaje desde el cual fue posible comenzar a cuestionar el estado natural de las cosas, suponiendo esto, entre otras cuestiones, el modo en que el Estado se relaciona con los pueblos indigenas (Castelnuovo, 2012). En otras palabras, lo que este discurso habilita es una nueva fórmula para los pueblos de reivindicar ante el Estado y en ese mismo sentido, de relacionarse con este.

Aunque también es dable reconocer que la difusión y promoción de los derechos impactó, como ya hemos señalado, tanto en la subjetividad de las mujeres y las relaciones entre los géneros a través de la generación de una conciencia de los derechos que las asisten como 
indígenas y ciudadanas, como además brindándoles elementos para traducir y enmarcar las transformaciones a las que están sujetas las comunidades y sus miembros como parte de un proceso local, regional y global. A través de la adopción del discurso de derechos de los pueblos y de la equidad de género, las mujeres también han logrado consolidar y crear alianzas con agencias de desarrollo en beneficio de sus propios intereses.

Si bien son muchas las mujeres guaraníes que consideran que las diferencias entre hombres y mujeres se han acortado y reconocen varios cambios con respecto a normas tradicionales que eran desventajosas para las mujeres, en una escala extra comunitaria, fundamentalmente a nivel de las organizaciones interétnicas zonales o regionales, son muy pocas las mujeres indigenas que logran hacer escuchar sus voces.

Solo cuando los pueblos indígenas reconozcan que las mujeres han caminado a su lado históricamente y que su conquista de nuevos espacios no los excluye sino que los unifica, será posible afirmar que la búsqueda y lucha para la construcción de una vida más justa que persiguen los pueblos, incluye los derechos de las mujeres. Sin embargo, esto no supone desconocer la emergencia de las mujeres guaraníes como actoras políticas que reclaman derechos propiamente de género. Pues ellas han logrado articular, a partir de la defensa de su pertenencia étnica, reclamos asociados con asumir nuevas relaciones y posiciones al interior de sus pueblos.

A modo de conclusión, me interesa destacar la importancia de combinar una perspectiva etnohistórica con el trabajo etnográfico del presente para explicar y dar cuenta de los procesos de cambio en largos períodos con respecto a la participación de las mujeres guaraníes. Pues, como espero haber demostrado, la adopción de este enfoque brinda una nueva lente para pensar procesos de cambio social y cultural vinculados con la promoción y difusión de una cultura de los derechos al interior de las comunidades y pueblos indígenas.

\section{Referencias}

Agencia de noticias Redaf. (2011, julio 5). Las mujeres indígenas tienen una relación bastante equitativa con los hombres., Entrevista a Hirsch S. M. Disponible en: http:redaf.org.ar/noticias / ?p=4095 
Betrisey, N. D. (2006). Mujeres indígenas y participación política en América Latina. En: La mujer como sujeto de acción politica (pp. 77-86). Sevilla, España: Centro de Estudios Andaluces.

Bonfil Sánchez, P. (2003). ¿Obedecer calando o mandar obedeciendo? La conquista de la palabra entre lideresas indígenas. México Indigena, 2 (5), 6-14.

Boserup, E. (1970). Woman's Role in Economic Development. London: George Allen \& Unwin.

Braunstein, J. (1983/1978). Algunos rasgos de la organización social de los indigenas del Gran Chaco, Trabajos de Etnología 2, 18-173.

Cabezas Gonzáles, A. (2012, marzo). Mujeres Indígenas constructoras de región: desde América Latina hasta Abya Yala. Internationala, 4 (6), 12-24 .

Castelnuovo, B. N. (2010). Las mujeres guaranies en su encuentro con el desarrollo. Una etnografia sobre su participación politica. Tesis de maestría no publicada. Maestría en Antropología Social, IDES/IDAES, Universidad de San Martín.

Castelnuovo, B. (2012). Mujeres guaranies y desarrollo en el noroeste argentino. Tesis doctoral no publicada. Filosofia y Letras, Universidad de Buenos Aires.

Clastres, P. (1974). La Société contre l'État. París: Éditions de Minuit.

Combes, I y D. Villar. (2004). Aristocracias chané. "Casas" en el Chaco argentino y boliviano. Journal de la société des américanistes. 90 (2), 63-102. Disponible en: http://jsa.revues.org/index1664.html.

Cunningham, K. M. (2003). Las mujeres indígenas en el derecho internacional de los pueblos indigenas. Memoria, Identidad y género, 174, 22-25.

Deledicque, M. (2007). Informe Final Estudio de Caso 2, UTD, Gral. Mosconi, Salta. Reino Unido: Consejo de Investigaciones Sociales y Económicas (ESRC), Programa de Acción Pública No Gubernamental (NGPA), LSE, University of Bath.

De Nino, B. (1912). Etnografía Chiriguana. La Paz: Tipografia Comercial de Ismael Argote.

Gianecchini, D. (1996/1898). Historia natural, etnografia, geografía, lingüística del Chaco boliviano. Tarija, Bolivia: Edición del Fondo de Inversión Social, Centro Eclesial de Documentación.

Gordillo, G. (2010). Deseando otro lugar: Re-territorializaciones guaraníes. En Gordillo G. y S. Hirsch (Comps.). Movilizaciones indigenas e identidades en disputa en la Argentina (pp. 207-236). Buenos Aires: La Crujia,.

Hernández, R. A (2001, octubre). Entre el etnocentrismo feminista y el esencialismo étnico. Las mujeres indígenas y sus demandas de género. Debate Feminista, 24 (12), 206-229.

Hernández, R. A. y Canessa, A. (Eds.). (2012). Género, Complementariedades y Exclusiones en Mesoamérica y los Andes. Quito, Ecuador: IWGIA (Serie Testimonios), Abya Yala. 
Hirsch, M. S. (1991). Political organization among the Isoceño indians of Bolivia. Tesis de doctorado. Los Angeles: University of California,.

Hirsch, M. S. (2003). Las mujeres guaraníes de Salta en la esfera doméstica y pública: una aproximación antropológica. En Runa. XXIV (pp. 213-232). Buenos Aires: Instituto de Ciencias Antropológicas, Facultad de Filosofia y Letras, Universidad de Buenos Aires.

Hirsch, M. S. (2008). Maternidad, trabajo y poder: cambios generacionales en las mujeres guaranies del norte argentino. En Hirsch, M. S. (Coord.). Mujeres indigenas en la Argentina. Cuerpo, trabajo y poder (pp. 231-251). Buenos Aires: Biblos.

Kidd, W. S. (1995). Relaciones de género entre los pueblos minimalistas del Chaco paraguayo: una perspectiva teórica y una consideración de los cambios actuales. Suplemento Antropológico, XXX (1-2), 7-42.

Magrassi, G. (1968). Censo Nacional. Tomo II provincias de Chaco, Formosa, Jujuy, Misiones, Salta y Santa Fe. Resultados provisorios, Censo 1967-68. Ministerio del Interior. Buenos Aires: Primera Parte: Monografias.

Méndez Torres, G. (2009). Miradas de género de las mujeres indígenas en Ecuador, Colombia y México. En Pequeño, A. (Comp.). Participación y políticas de mujeres indigenas en América Latina (pp. 53-71). Quito: FLACSO- Ministerio de Cultura.

Métraux, A. (1935). La mujer en la vida social y religiosa de los indios chiriguanos. En Trabajos Cientificos XXVI, Congreso Internacional de Americanistas. Tomo I (pp. 416-430). Sevilla: S. Aguirre Impresor.

Métraux, A. (1948). Tribes of the Eastern Slopes of the Bolivian Andes. Chiriguano and Chané. En J. H. Steward (Ed.). Handbook of South American Indians III (pp. 465-485). Washington: Smithsonian Institution.

Nordenskiöld, E. (2002/1912). La vida de los indios. Bolivia: APCOB.

Overing, J. (1986). Men control women? The 'Catch 22' in Gender Analysis. International Journal of Moral and Social Studies, 1, 135-156.

Página 12. (2011, febrero 28). Hay muy baja incidencia de violencia sexual entre indigenas. Entrevista a Hirsch S. M. Disponible en: http://pagina12.com.ar/ imprimir/diario/dialogos/21-163

Palomo, N. (Comp.). (1996). Influencias del zapatismo en las mujeres indigenas. México: Comisión de Seguimiento de Mujeres de la ANIPA, K’inal Antsetik.

Pequeño, A. (2009). Introducción. En: Pequeño, A. (Comp.). Participación y politicas de mujeres indigenas en América Latina (pp. 9-25). Quito: FLACSO, Ministerio de Cultura.

Perrin, M. y Perruchon, M. (1997). Introducción. En Mader, Elke et al., (Eds.). Complementariedad entre hombre y mujer. Relaciones de género desde la perspectiva amerindia (pp. 7-22). Quito: Abya-Yala, $\mathrm{N}^{\circ} 43$. 
Romay Mendoza, A. (2012). Experiencia de las mujeres nahuas. En Hernández, R. A. y Canessa, A. (Eds.). Género, Complementariedades y Exclusiones en Mesoamérica y los Andes (pp. 294-301). Quito: IWGIA (SerieTestimonios), Abya Yala.

Saignes, T. (2007/1982). Mestizos y salvajes: los desafios del mestizaje en la frontera chiriguano (1570-1620). En Combès, I. (Comp.). Historia del pueblo guaraní (pp. 183-230). Bolivia: Plural.

Sánchez, C. (2003). Identidad, género y autonomía. Las mujeres indígenas en el debate. Memoria, Identidad y género, 174, 12-18.

Sánchez, M. (2012). Los retos de los liderazgos femeninos en el movimiento indigena de México: la experiencia de la ANIPA. En Hernández, A. y Canessa, A. (Eds.). Género, Complementariedades y Exclusiones en Mesoamérica y los Andes (pp. 254-273). Perú: IGWIA (Serie Testimonios), Abya-Yala y British Academy.

Sánchez, N. M. (2003). Derechos de la mujer indigena. Memoria, Identidad y género, $174,12-18$.

Segato, R. L. (2003). Uma agenda de ações afirmativas para as mulheres indigenas do Brasil. Serie de Antropología. Departamento de Antropología de la Universidad de Brasilia, 326 (nova versao), 1-64.

Susnik, B. (1968). Chiriguanos I. Dimensiones etnosociales. Asunción: Museo Etnográfico Andrés Barbero.

Ulloa, A. (2007). Introducción: Mujeres indigenas: dilemas de género y etnicidad en los escenarios latinoamericanos. En Donato, L. M., Escobar, E. M., Escobar, P., Pazmiño, A. y Ulloa, A. (Eds.). Mujeres indigenas, territorialidad y biodiversidad en el contexto latinoamericano (pp. 17-33). Bogotá: Universidad Nacional de Colombia.

Valladares, L. R. y Pérez Cárdenas, L. (2010). Las encrucijadas de la ciudadanización de las mujeres indigenas: Experiencias de la ñahñu del Municipio de Amealco, Querétaro. En Castro Domingo, P. y Tejera Gaona, H. (Coords.). Participación y ciudadanía en México (pp. 109-144). México: Universidad Autónoma Metropolitana, Unidad Iztapalapa, Biblioteca de Alteridades, 17, Cultura y Política.

Velásquez Cepeda, M. C. (2003). ¿Mujeres indigenas gobernando en Municipios de Oaxaca?. México Indigena, 2 (5), 24-31.

Vianey Vargas, L. (2012). Las mujeres de Tlahuitoltepec Mixe: frente a la impartición de la justicia local y el uso del derecho internacional (2000-2008). En Hernández, R. A. y Canessa, A. (Eds.). Género, Complementariedades y Exclusiones en Mesoamérica y los Andes (pp. 302-318). Quito: IWGIA (Serie Testimonios), Abya Yala.

Villar, D. y Bossert, F. (2008). La jefatura entre los chané del noroeste argentino. En Liderazgo, representatividad y control social en el Gran Chaco (pp. 275-284).

Corrientes: Eudene, Universidad Nacional del Nordeste. 
VV. AA. (2007). Mujeres dirigentes indígenas. Relatos e Historias de vida. Cultura ciudadana y diversidad. Buenos Aires: Secretaría de Cultura, Presidencia de la Nación.

\section{Cómo citar este artículo}

Castelnuovo, N. (2015) Dándole la palabra: nuevas modalidades de liderazgo entre mujeres guaraníes del noreste argentino. Universitas Humanística, 79, 89-113. http://dx.doi.org/10.11144/Javeriana.UH79.dpnm 